\title{
Study of peptide on-line complexation with transition-metal ions generated from sacrificial electrodes in thin-chip polymer microsprays
}

\author{
Tatiana C. Rohner ${ }^{\dagger}$ and Hubert H. Girault* \\ Laboratoire d'Electrochimie Physique et Analytique, Ecole Polytechnique Fédérale de Lausanne, 1015 Lausanne, Switzerland \\ Received 4 January 2005; Revised 27 February 2005; Accepted 27 February 2005
}

\begin{abstract}
A miniaturized polymer electrospray-type interface is used to study metal-ion chelation with model peptides. Taking advantage of the intrinsic electrochemical behavior of electrospray, a sacrificial electrode is used to generate at the same time electrospray and transition-metal ions coming from the anodic dissolution of the electrode. The microspray interface provides enhanced mass transport due to its small dimensions, increasing the yield of possible reactions, in particular complex formation. Transition-metal electrodes, e.g. copper, zinc, nickel, iron and silver, are used to obtain on-line complexation with model peptides. It is demonstrated that the use of inreservoir sacrificial electrodes is an efficient way to generate metal ions in order to form and study complexes with peptides, avoiding the addition of metallic salts. Copyright (C) 2005 John Wiley \& Sons, Ltd.
\end{abstract}

Metal ions are involved in many biological functions in proteins. They usually enhance the structural stability of biomolecules in a required conformation for further reaction, like bringing reacting groups together into correct relative orientation for reaction, or undergoing oxidation to insure the catalytic role of the enzyme. In most cases, metal-ion binding to biological molecules is remarkably selective regarding metal species and also their oxidation state, e.g. $\mathrm{Fe}^{3+}, \mathrm{Fe}^{2+}$. Unlike the alkali and alkaline-earth metals, where the bonding is predominantly electrostatic, coordination complexes of transition metals with peptides exhibit binding with a substantial degree of covalence, ${ }^{1}$ the likely ligands depending on the intrinsic coordination properties of the metal.

While analytical studies concerning metalloproteins aim at fully understanding the biological role of metals and its significance from a biochemical point of view, a second outlook is based on the analytical utility of metal-protein complexation. The affinity of metals towards specific functional groups can be used to obtain a specific selection from a protein mixture. Metal complexation is indeed mainly used as an affinity tool. Immobilized metal ion affinity chromatography (IMAC), also called metal chelate affinity chromatography (MCAC), was first successfully demonstrated in 1975 by Porath et al. for human serum proteins. ${ }^{2}$ To carry out IMAC, metal ions, such as $\mathrm{Zn}^{2+}, \mathrm{Ni}^{2+}$ or $\mathrm{Cu}^{2+}$, are bound to solid matrices. Stable complexation is usually obtained with histidine, tryptophan, and cysteine residues of peptides or

${ }^{*}$ Correspondence to: H. H. Girault, Laboratoire d'Electrochimie Physique et Analytique, Ecole Polytechnique Fédérale de Lausanne, 1015 Lausanne, Switzerland.

E-mail: hubert.girault@epfl.ch

${ }^{\top}$ Current address: Analytical and Imaging Sciences, Novartis Institutes for BioMedical Research, 4002 Basel, Switzerland. proteins. Binding typically occurs at neutral or slightly alkali $\mathrm{pH}$, whereas desorption/elution generally occurs via imidazole gradients or under acidic conditions.

To study the affinity and the specificity of complexation, a mixture of the metal salt and the biological compound of interest is analyzed by mass spectrometry (MS). To further examine the structural changes induced by the metal chelation, the stability and the fragmentation pattern of the complexes are studied by tandem mass spectrometry (MS/MS). Metal cations have actually been found to direct amino acid and peptide fragmentations, thus providing information both on the side chains and on the amino acid sequence. $^{3,4}$ As electrospray ionization (ESI) is a soft ionization method, ESI-MS analysis of metal cation/peptide complexes is straightforward and the strength of the complexes can be assessed. Complexation of metals was first used with ESI-MS to enhance the detection of amino acids. The amino acids were analyzed in the form of ternary complexes with a divalent transition metal and a neutral ligand, e.g. 2,2'-bipyridine or 1,10-phenanthroline, ${ }^{5-7}$ used to enhance the complexation and to prevent the formation of neutral binary complexes. ${ }^{6,8}$ Metal complexation has also been explored as an alternative to protonation for ESI-MS analyses of pharmaceutical compounds. ${ }^{9}$

In addition to the softness of the ionization, another interesting feature of ESI is its electrolytic nature. An ESI source can indeed be seen as a special kind of electrochemical cell, ${ }^{10}$ where the anode is the electrode in contact with the analyte solution in the emitter and the mass spectrometer, the cathode (in positive ion mode, polarity being reversed in negative ion mode). The conduction through this 'cell' is supported by the motion of ions in the solution and then in the gas phase before reaching the counter electrode, i.e. the 
mass spectrometer, the limiting step being the droplet ejection that determines the so-called electrospray current $i_{E S} \cdot{ }^{10}$ From an electrochemical standpoint, the ESI source has been demonstrated to behave as a controlled-current system. The law of continuity of the current implies that the Faraday current $i_{F}$ associated with the oxidation of species from the electrolyte solution at the electrospray electrode is always equal to the spray current $i_{E S}$. In positive ion mode, compounds with the lowest oxidation potential will be oxidized first and, if the current level is not sufficient, those with a higher oxidation potential will then undergo oxidation, in order to keep the current flowing. Since the first proof of principle of this electrochemical feature by the electrogeneration of $\mathrm{Zn}^{2+}$ ions using a zinc emitter, ${ }^{11}$ it has also been demonstrated that metal ions could be deposited on or liberated from the electrospray electrode simply by switching from negative (for the plating step) to positive ion mode (for the stripping step), ${ }^{12}$ the amount of metal ions generated per unit time being known by the $i_{E S}$ current readout, which is constant under stable spray conditions. Phenanthroline complex formation induced by the oxidation of metal electrodes has previously been demonstrated by Van Berkel and co-workers. ${ }^{13,14}$

As suggested by Van Berkel, ${ }^{14}$ this method avoids the use of a metallic salt (e.g. $\mathrm{CuSO}_{4}$ ), therefore preventing signal suppression induced by anions introduced together with the metal ion. ${ }^{15}$ The goal of this study is to use the intrinsic electrochemical behavior of ESI to generate metal ions directly from the electrospray anode, used in a sacrificial way, and to highlight the specific advantages and drawbacks of sacrificial electrodes for peptide-metal complex studies. For this purpose, a miniaturized microspray interface, already described by Gobry et al., ${ }^{16}$ is used in order to take advantage of the enhanced mass transport induced by the small dimensions of the device.

The feasibility and efficiency of electrogeneration, and the subsequent adduct formation, are investigated for two model peptides and five different metals that are known to chelate to peptides. Residues such as histidine and cysteine are considered to be better metal-binding ligands than amides in peptides, and so a structure that involves a metal chelating to these groups and the neighboring amide(s) is more favorable than those involving only amide groups. ${ }^{17}$ Therefore, human angiotensin II (DRVYIHPF) and a synthetic peptide (AIKCTKF) have been tested. It must be stressed that the first contains one histidine (without cysteine) and the second one free cysteine (without histidine).

The best candidates to evaluate this method are copper and zinc electrodes, which are the most abundant metals involved in metalloproteins and also the easiest to oxidize in view of their redox potentials (see Table 1). In addition, their low solvation times favor the complexation (see Table 2). Copper complexation with proteins is well established for protein quantification via the Biuret reaction, ${ }^{18-22}$ and zinc occurs naturally in many metalloproteins, such as carbonic anhydrase, and several proteases and isomerases. ${ }^{23}$ Zinc is also widely used for the purification of histidine-tagged proteins.

Other common metal complexes have been studied using nickel, silver and iron electrodes. Although only four proteins or enzymatic systems are currently known to contain
Table 1. Redox potential of different redox couples involved in on-line metal-peptide complexation ${ }^{38}$

\begin{tabular}{lc}
\hline & $E_{0}(\mathrm{~V})$ \\
\hline $\mathrm{O}_{2}+4 \mathrm{H}^{+}+4 \mathrm{e}^{-}=\mathrm{H}_{2} \mathrm{O}$ & 1.229 \\
$\mathrm{Ag}^{+}+\mathrm{e}^{-}=\mathrm{Ag}$ & 0.799 \\
$\mathrm{Fe}^{3+}+\mathrm{e}^{-}=\mathrm{Fe}^{2+}$ & 0.77 \\
$\mathrm{Cu}^{+}+\mathrm{e}^{-}=\mathrm{Cu}$ & 0.52 \\
$\mathrm{Cu}^{2+}+2 \mathrm{e}^{-}=\mathrm{Cu}$ & 0.34 \\
$\mathrm{Ni}^{2+}+2 \mathrm{e}^{-}=\mathrm{Ni}$ & -0.257 \\
$\mathrm{Fe}^{2+}+2 \mathrm{e}^{-}=\mathrm{Fe}$ & -0.44 \\
$\mathrm{Zn}^{2+}+2 \mathrm{e}^{-}=\mathrm{Zn}$ & -0.76 \\
\hline
\end{tabular}

Table 2. Solvation times corresponding to mean lifetimes of a single water molecule in the first coordination sphere of a given metal ion

\begin{tabular}{llllll}
\hline & $\mathrm{Cu}^{2+}$ & $\mathrm{Zn}^{2+}$ & $\mathrm{Fe}^{2+}$ & $\mathrm{Ni}^{2+}$ & $\mathrm{Ag}^{+}$ \\
\hline Solvation time (s) & $10^{-9}$ & $10^{-7}$ & $10^{-6}$ & $10^{-4}$ & - \\
\hline
\end{tabular}

functional redox nickel, ${ }^{23}$ affinity chromatography of histidine-containing peptides is based on the high affinity of $\mathrm{Ni}^{2+}$ for the imidazole moiety. The interaction of iron ions and sulfides is common in all biological systems, and these groups are found at the active centers of a wide variety of redox and catalytic proteins. Lastly, despite its use as an antibacterial agent, silver is not involved in any biochemical function; however, its complexation is implicated in twodimensional (2D) gel silver staining.

\section{EXPERIMENTAL}

Human angiotensin II (Bachem, Bubendorf, Switzerland) (average MW 1046.1; pI 6.74), the cysteinyl peptide (average MW 810.0; pI 9.32), and methanol (Merck, Darmstadt, Germany) were used without any further purification. Deionized water $(18.5 \mathrm{M} \Omega$ ) was prepared using a Milli-Q system from Millipore (Bedford, MA. USA). Peptide solutions consisted of $50 \mu \mathrm{M}$ in 50:50 (v/v) MeOH/ $\mathrm{H}_{2} \mathrm{O}$.

Metal-ion on-line complexation is carried out using a Vshaped microspray interface, shown schematically in Fig. 1(a), which consists of a single microchannel $(40 \times 100 \mu \mathrm{m})$ and a
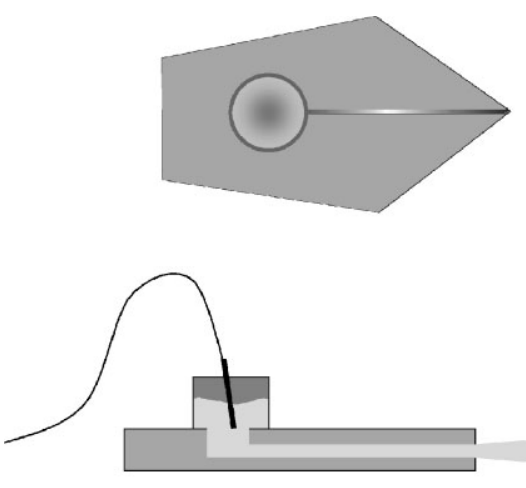

(a)

(b)

Figure 1. (a) Top view of the microspray chip and (b) microspray in use with the metal electrode in the inlet reservoir. 


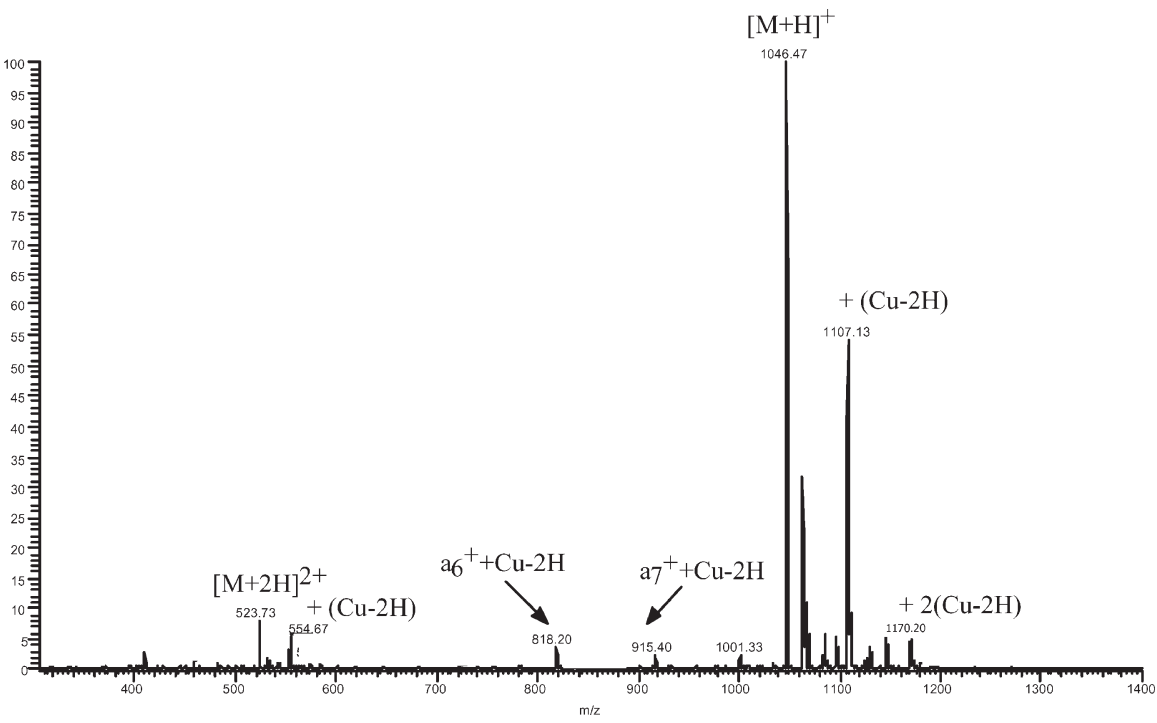

Figure 2. Full scan mass spectrum from the infusion of angiotensin II using a copper electrode $(\mathrm{t}=3 \mathrm{~min}) . \quad[\mathrm{M}+\mathrm{H}]^{+}=1046.47 ; \mathrm{m} / \mathrm{z}(1: 1$ complex $)=1107.13 ; \mathrm{m} / \mathrm{z} \quad(1: 2$ complex) $=1170.20$.

reservoir fixed at its inlet. This polymer microspray interface design and its fabrication have been described previously. ${ }^{16,24,25}$

The chip is lined up with respect to the entrance of the LCQ Duo ion trap mass spectrometer (Finnigan, San Jose, CA, USA). Then, the chip reservoir is loaded with $75 \mu \mathrm{L}$ of a peptide solution. The metal electrode, used as the microspray electrode, is sanded and rinsed with ethanol and methanol. The electrode, connected to the high-voltage supply of the mass spectrometer, is inserted into the solution reservoir (see Fig. 1(b)).

After the mass spectrometer power supply onset $(U=3.2 \mathrm{kV})$ and starting the mass spectrum acquisition, the chip is moved closer to the entrance of the mass spectrometer to generate electrospray and thus to start the dissolution of the electrode and the subsequent complexation reaction. When the electrospray is on, the solution is pumped by pressure-driven flow induced by the level of liquid present in the reservoir, electroosmotic flow and the electrospray process. This system is, from a mass-transport standpoint, different from the one used by Van Berkel et al.: ${ }^{13}$ The solution volume is indeed much larger than in the pulled capillary used by Van Berkel, and the flow rate has been estimated to $500 \mathrm{~nL} / \mathrm{min}(25 \mathrm{~nL} / \mathrm{min}$ for the pulled capillary).

A nanoamperometer is used to monitor the current and its stability. The current is fixed at $30 \mathrm{nA}$ by adjusting the distance between the microspray outlet and the entrance to the mass spectrometer for each experiment. Control of this parameter is a key point in order to be able to qualitatively compare the complexation reactions. Metal salts $\left(\mathrm{CuSO}_{4}\right.$, $\mathrm{ZnCl}_{2}, \mathrm{AgNO}_{3}, \mathrm{NiCl}_{2}, \mathrm{FeCl}_{2}$ ) were used not only to check the mass shift obtained with the electrogenerated ions, but also to evaluate the 'yield' of electrogeneration against the addition of salts. Based on experiments performed with $100 \mu \mathrm{M} \mathrm{CuSO} / 50 \mu \mathrm{M}$ peptide solutions, the estimated concentration of the electrogenerated ions should be within the same range.
To simplify the assignment of the adducts and the related ions in the mass spectra presented here, only the mass shifts have been mentioned.

\section{RESULTS AND DISCUSSION}

\section{On-line complexation with a copper electrode}

When the copper electrode is used for ESI of the angiotensin solution, a 1:1 complex is observed a few seconds after the onset of electrospray, then the 2:1 complex, roughly $1 \mathrm{~min}$ later (see Fig. 2). The shift observed due to the first addition of copper corresponds to the monoisotopic mass of the metal minus two hydrogens (see Table 3), which is consistent with the results obtained by Hutchens and Allen, ${ }^{26}$ as well as $\mathrm{Hu}$ and Loo. ${ }^{27}$ For the 2:1 adduct, the shift corresponds to $2(\mathrm{Cu}-$ $2 \mathrm{H})$. The charging of the peptide chain due to the $\mathrm{Cu}^{2+}$ addition is certainly compensated for by the removal of two protons from the backbone. Li et al. ${ }^{28}$ have demonstrated that the protons, which are lost for this charge compensation, are likely to be different from those carrying the charge of the native peptides. The deprotonation can occur at the Cterminal carboxylic group or at the phenol moiety of the tyrosine residue, ${ }^{29}$ but the most likely source is the protons from the amide groups coordinated to the metal ion.

Complex fragments $\left[\mathrm{a}_{6}+(\mathrm{Cu}-2 \mathrm{H})\right]^{+}$and $\left[\mathrm{a}_{7}+(\mathrm{Cu}-2 \mathrm{H})\right]^{+}$ are also generated when spraying with the copper electrode, although the current has been found to be low and stable during the whole experiment, apart from any fragmentation

Table 3. Mass shifts (Th) obtained with the different electrodes, with the metal most abundant isotope masses

\begin{tabular}{lccccc}
\hline & $\mathrm{Cu}$ & $\mathrm{Zn}$ & $\mathrm{Ni}$ & $\mathrm{Fe}$ & $\mathrm{Ag}$ \\
\hline Angiotensin II & 60.95 & 61.90 & 55.83 & 53.82 & - \\
AIKCTPF & 61.89 & 61.84 & 55.94 & 55.97 & 105.94 \\
Isotopic mass & 62.93 & 63.93 & 57.93 & 55.93 & 106.90 \\
\hline
\end{tabular}




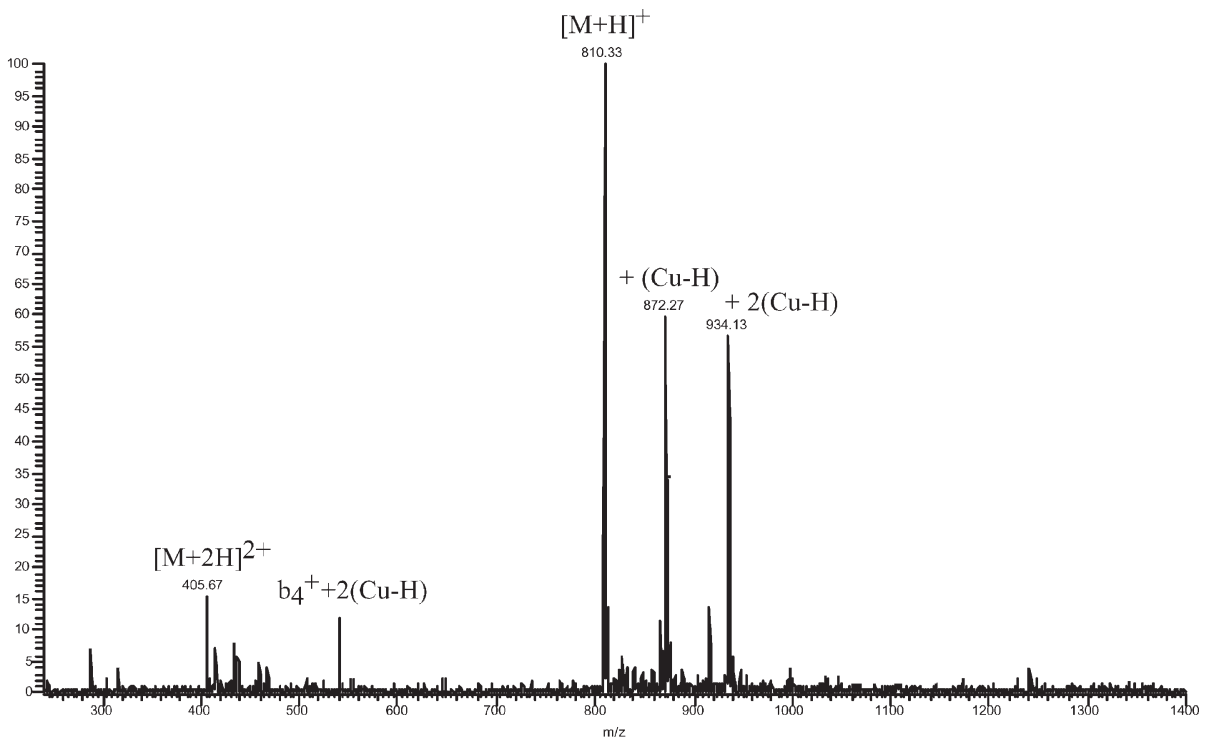

Figure 3. Full scan mass spectrum from the infusion of AIKCTKF using a copper electrode $\quad(\mathrm{t}=3 \mathrm{~min}) . \quad[\mathrm{M}+\mathrm{H}]^{+}=810.33 ; \quad \mathrm{m} / \mathrm{z} \quad(1: 1 \quad$ complex $)=872.27 ; \quad \mathrm{m} / \mathrm{z} \quad(1: 2$ complex $)=934.13$.

due to corona discharges. Even though these two single adduct a-type fragments are generated during the experiment, none of them are significant when MS/MS is performed on the adduct (data not shown). This observation rules out any gas-phase fragmentation. Thus the complexation itself is directly implicated in the formation of these fragments. Since these fragments were also generated when using $\mathrm{Cu}$ (II) salts, cupric ions could induce hydrolysis of the peptide backbone, as was pointed out by Sigel and Sigel. ${ }^{30}$

As illustrated in Fig. 3, the presence of the cysteine residue seems to have a great influence on copper chelation on the peptide. A single and a double adduct are each generated with a significant intensity, the double adduct signal being markedly higher than that of the angiotensin complex. Contrary to what is observed for angiotensin (see Table 3), the mass shift for the single adduct corresponds here to $(\mathrm{Cu}-\mathrm{H})$. For the double addition, the mass shift corresponds to $2(\mathrm{Cu}-\mathrm{H})$. Again, a fragment is formed, $\left[\mathrm{b}_{4}+2(\mathrm{Cu}-\mathrm{H})\right]^{+}$, and this is at the cysteine residue. These mass shifts have also been checked by MS analysis of a mixture of angiotensin II with $\mathrm{CuSO}_{4}$ salts (data not shown), ruling out any interference due to the electrogeneration of cuprous ions $\left(\mathrm{Cu}^{+}\right)$ and their complexation before dismutation. Since the deprotonation does not compensate for the charge carried by the cupric ion, the reduction of the latter to cuprous ion $\left(E_{0}=0.159 \mathrm{~V}\right.$ vs. SHE) in the presence of the thiol moiety when complexation occurs is the most likely reaction, as already demonstrated by several groups. ${ }^{31-33}$

For each peptide, a decrease in the signal-to-noise ratio has also been observed, which was not observed for microspray generation with a platinum wire. Surprisingly, the same additions were observed by Jiao and Freiser, ${ }^{34}$ although copper salts were used. They attributed these peaks to contamination coming from the salt sample. However, this is not likely with a sacrificial electrode. Hence, this phenomenon could be linked to the complexation reaction or to gasphase reactions inherent to ESI.

\section{On-line complexation with a zinc electrode}

A strong complexation occurs between $\mathrm{Zn}^{2+}$ and angiotensin, as shown in Fig. 4. A double adduct is also produced, even though its intensity is very weak compared with the corresponding copper adduct signal. The mass shift is equivalent to $(\mathrm{Zn}-2 \mathrm{H})$ for the single adduct, which is in agreement with the results of $\mathrm{Hu}$ and $\mathrm{Loo}$ and $\mathrm{Loo}$ and COworkers, ${ }^{27,35}$ and $2(\mathrm{Zn}-2 \mathrm{H})$ for the double adduct. In contrast to the experiments with copper, no fragment is observed in the full scan mass spectrum (see Fig. 2). As expected from its use in IMAC, histidine is a primary anchor for zinc, since a very high tagging yield is obtained despite a lower solvation time than for the cupric ion (see Table 2). When the cysteinyl peptide solution is infused, a 1:1 and a 1:2 complex are also observed, the latter being lost in the background (see Fig. 5). The tagging is less efficient than in angiotensin II complexation. This could be due to the lower affinity of the zinc ion (borderline Lewis acid) for the thiol moiety of cysteine (soft Lewis base). As for angiotensin, the mass shifts of the single adduct and the double adduct correspond, respectively, to $(\mathrm{Zn}-2 \mathrm{H})$ and $2(\mathrm{Zn}-2 \mathrm{H})$.

\section{On-line complexation with a nickel electrode}

The complexation of nickel with angiotensin and the synthetic peptide is markedly less efficient (less than 7\%) than with the previous metals, as shown in Figs. 6 and 7. Similarly to zinc (see Table 3 ), the mass shifts correspond to (Ni-2H), which indicates that the charge of the metal cation is intact and is compensated for by the loss of two protons. Referring to Table 2, the nickel ion solvation time prevents a high complexation yield, but a longer time for reaction by lengthening the channel could help to compensate for this limiting step. The adduct signals are, however, intense enough for further analysis, such as MS/MS, to be carried out.

\section{On-line complexation with an iron electrode}

The complexation yield of angiotensin with iron is quite low, as shown in Fig. 8, with a mass shift of $(\mathrm{Fe}-2 \mathrm{H})$. Smith and 


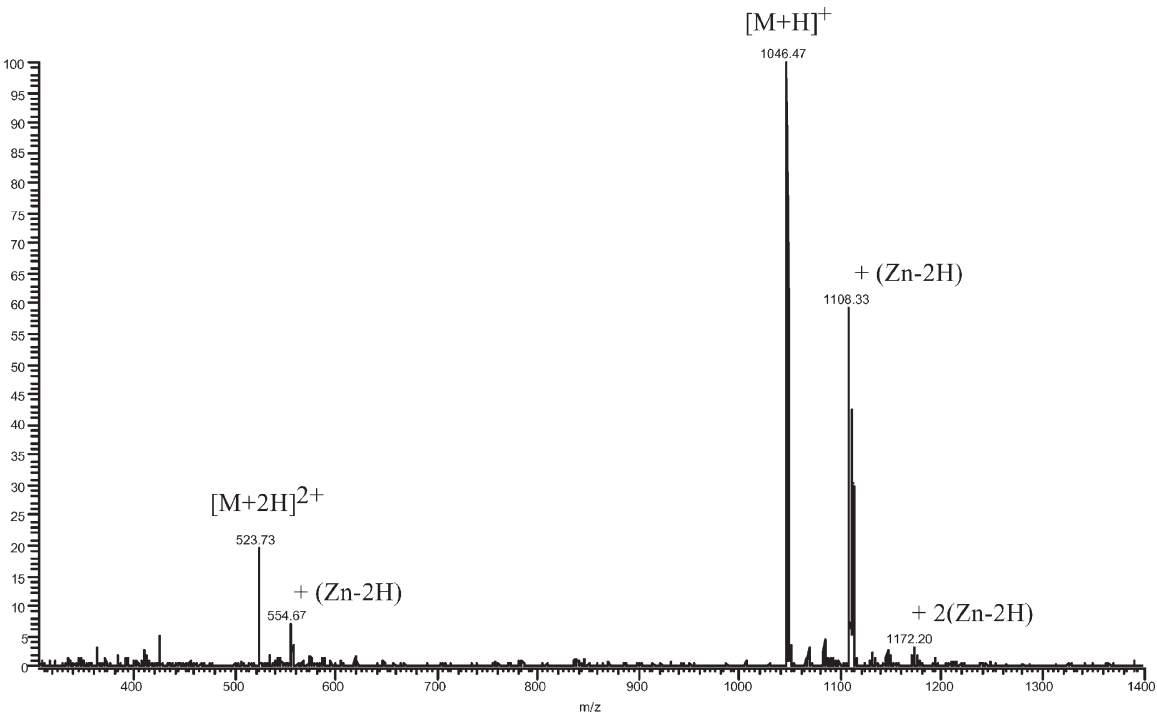

Figure 4. Full scan mass spectrum from the infusion of angiotensin II using a zinc electrode $(\mathrm{t}=4 \mathrm{~min}) .[\mathrm{M}+\mathrm{H}]^{+}=1046.47 ; \mathrm{m} / \mathrm{z} \quad(1: 1$ complex $)=1108.33 ; \mathrm{m} / \mathrm{z} \quad(1: 2$ complex) $=1172.20$.

Moini could also detect a high level of angiotensin-iron complex using a highly rusted iron wire as the electrospray electrode in an acidic medium. ${ }^{36}$ However, they found a mass addition corresponding to the metal monoisotopic mass. As shown in Fig. 9, the cysteinyl peptide complex mass also corresponds to the addition of the monoisotopic mass of iron. This last result is not in accordance with results obtained by Nemirovskiy et al., ${ }^{1,37}$ since they reported a $(\mathrm{Fe}-\mathrm{H})$ shift for a cysteinyl adduct, using the metallic salt. It must also be stressed that the mass shifts obtained with the nickel and iron cysteinyl peptide adducts are particularly similar. Investigations based on MS/MS analyses of these complexes will help to distinguish them through specific fragmentation pathways.

Iron complexation seems to be highly dependent on experimental conditions, involving either the metallic salt or the electrospray electrode. The low efficiency and the uncertain pathway of the iron chelation are based on the homogeneous reaction of ferrous ion with water and oxygen:

$$
2 \mathrm{Fe}^{2+}+3 \mathrm{H}_{2} \mathrm{O}+\frac{1}{2} \mathrm{O}_{2} \rightarrow 2 \mathrm{FeOOH}+4 \mathrm{H}^{+}
$$

which results in the precipitation of $\mathrm{FeOOH}$ on the electrode, i.e. rust, and many subsequent processes. ${ }^{38}$ Reaction (1) induces a $\mathrm{pH}$ drop, which could result in the appearance of the $[\mathrm{M}+3 \mathrm{H}]^{3+}$ in the spectrum (see Fig. 9). In addition, the formation of the oxide layer, observed after each experiment, decreases the amount of iron available for anodic dissolution. Some water oxidation should then take place in order to maintain the $i_{E S}$ level, thus inducing a $\mathrm{pH}$ drop. Thus, reaction (1) implies that the electrogeneration of $\mathrm{Fe}^{2+}$ for

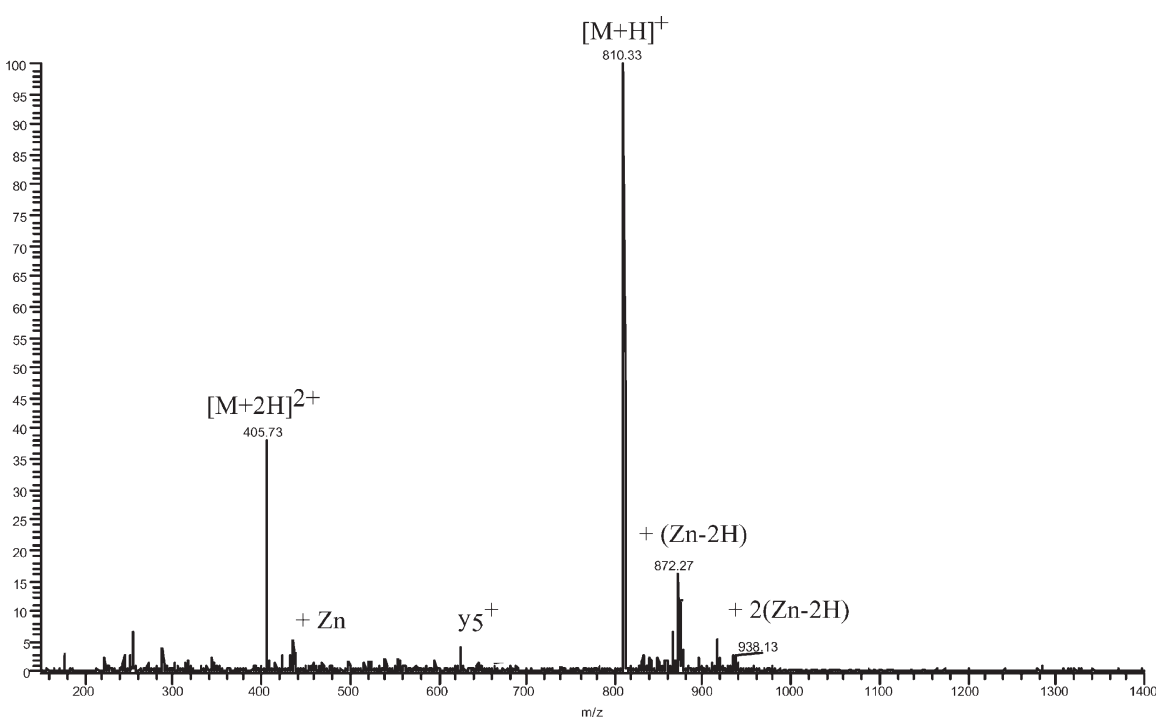

Figure 5. Full scan mass spectrum from the infusion of AIKCTKF using a zinc electrode $(\mathrm{t}=4 \mathrm{~min}) . \quad[\mathrm{M}+\mathrm{H}]^{+}=810.33 ; \mathrm{m} / \mathrm{z} \quad(1: 1 \quad$ complex $)=872.27 ; \mathrm{m} / \mathrm{z} \quad(1: 2$ complex) $=938.13$. 


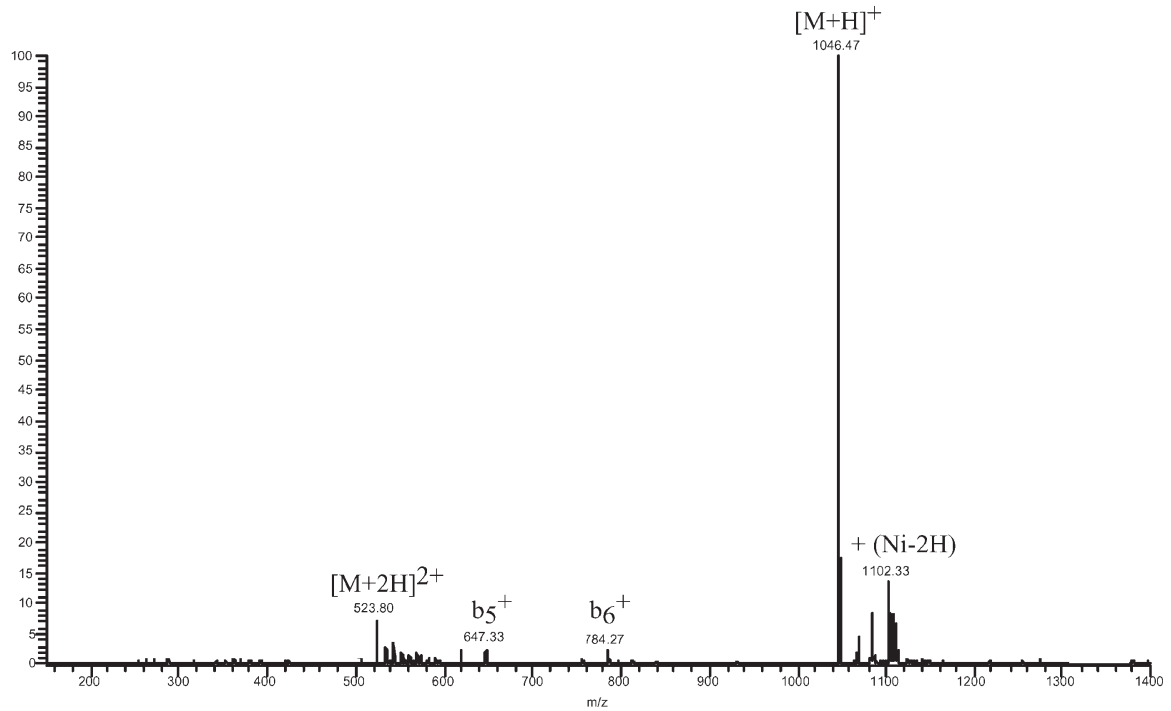

Figure 6. Full scan mass spectrum from the infusion of angiotensin II using a nickel electrode $(\mathrm{t}=4 \mathrm{~min}) .[\mathrm{M}+\mathrm{H}]^{+}=1046.47 ; \mathrm{m} / \mathrm{z}(1: 1 \mathrm{complex})=1102.33$.

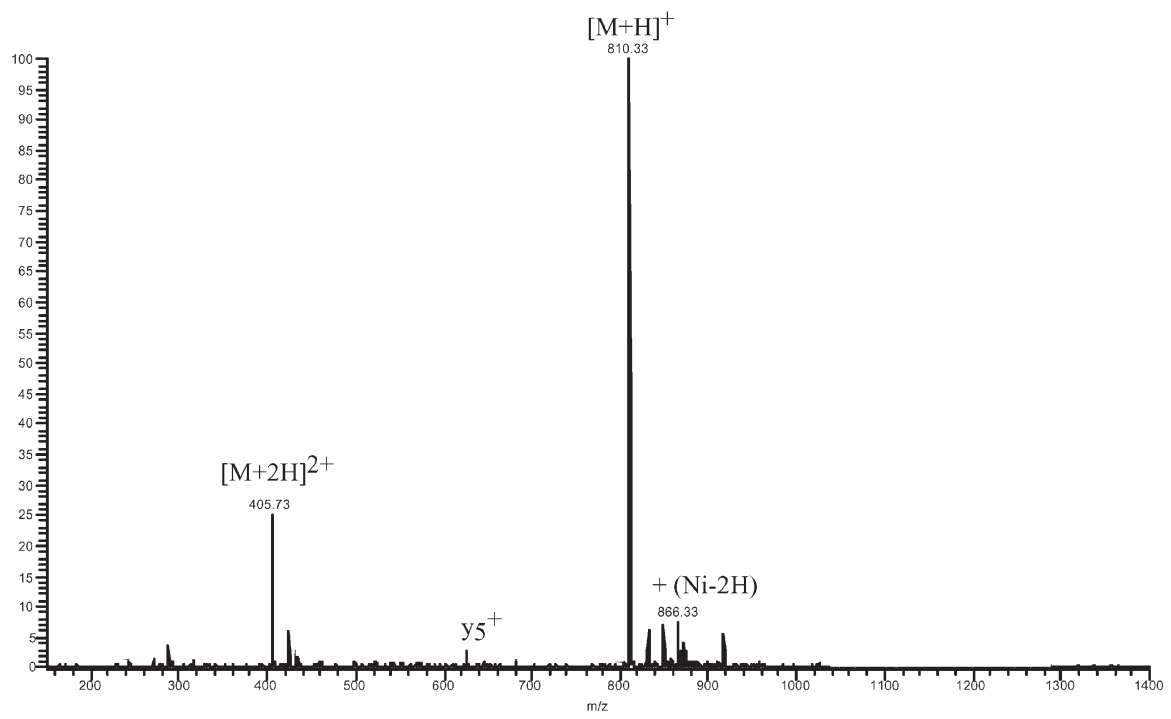

Figure 7. Full scan mass spectrum from the infusion of AlKCTKF using a nickel electrode $(\mathrm{t}=3 \mathrm{~min}) .[\mathrm{M}+\mathrm{H}]^{+}=810.33 ; \mathrm{m} / \mathrm{z}(1: 1$ complex $)=866.33$.

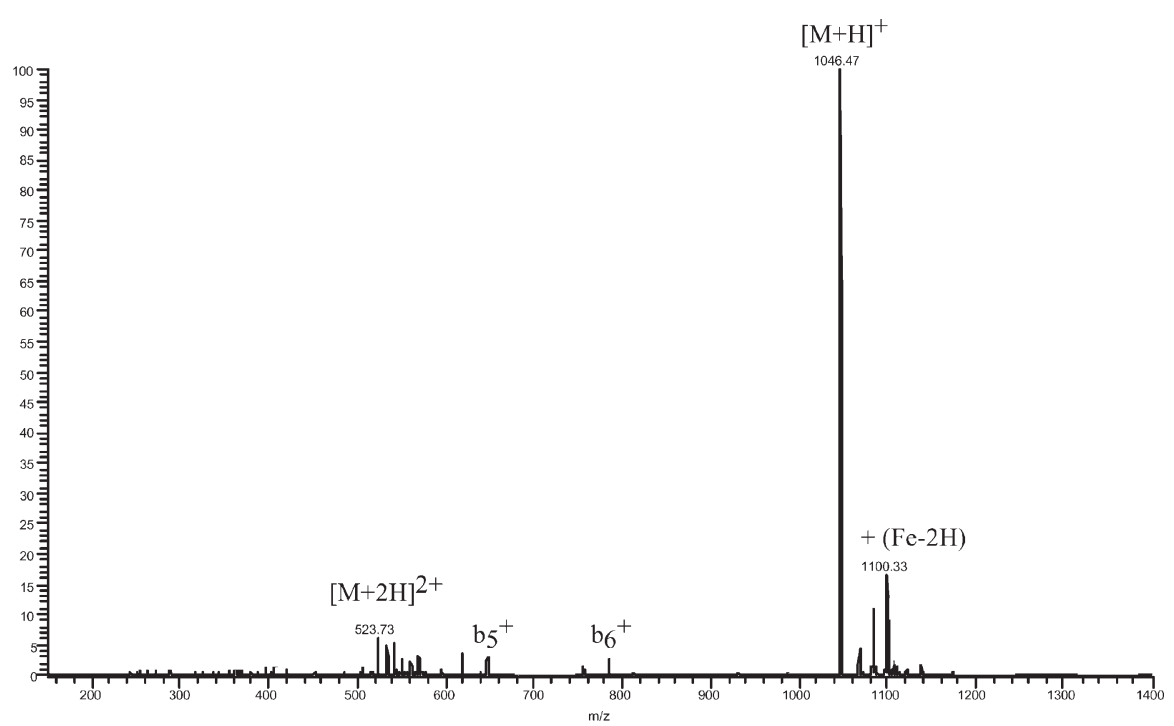

Figure 8. Full scan mass spectrum from the infusion of angiotensin II using an iron electrode $(\mathrm{t}=2 \mathrm{~min}) .[\mathrm{M}+\mathrm{H}]^{+}=1046.47 ; \mathrm{m} / \mathrm{z}(1: 1 \mathrm{complex})=1100.33$. 


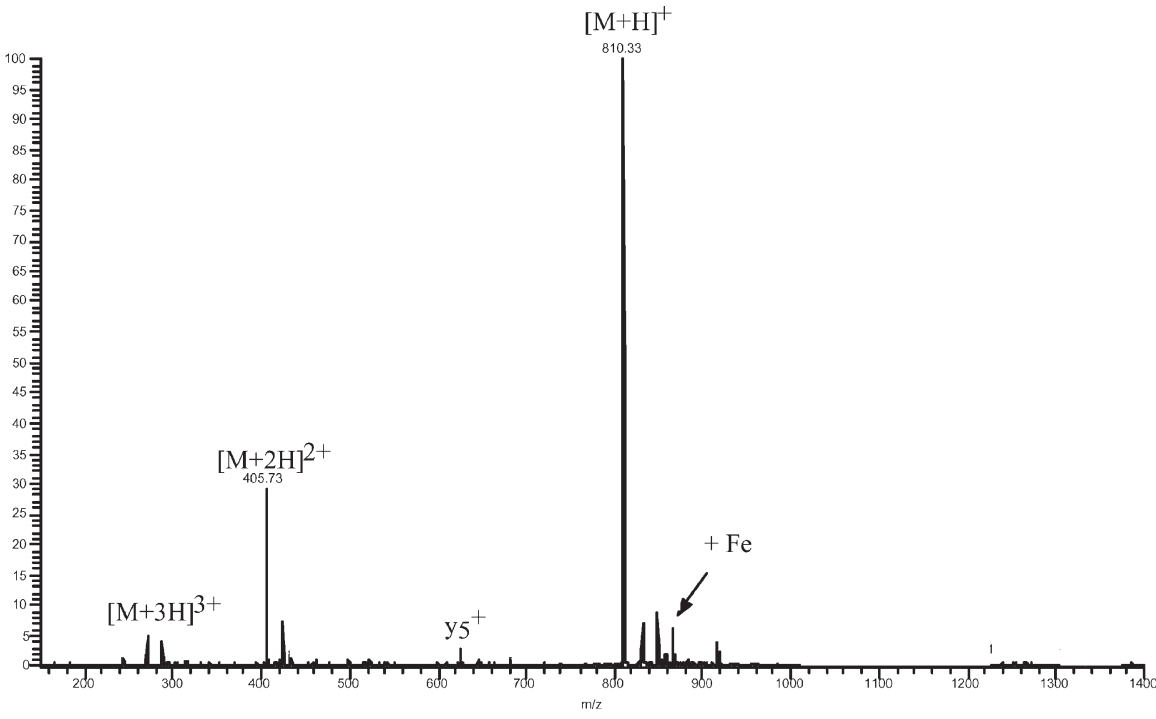

Figure 9. Full scan mass spectrum from the infusion of AlKCTKF using an iron electrode $(\mathrm{t}=3 \mathrm{~min}) .[\mathrm{M}+\mathrm{H}]^{+}=810.33 ; \mathrm{m} / \mathrm{z}(1: 1$ complex $)=866.33$.

complexation should be carried out in degassed solutions to hinder the passivation of the electrode.

Another pathway could be the reoxidation of ferrous ion to ferric ion. Since the oxidation state is increased, the coordination can be drastically modified. To identify whether the oxidation state of the iron could affect the efficiency of the complexation, $\mathrm{FeSO}_{4}$ and $\mathrm{FeCl}_{3} \cdot 6 \mathrm{H}_{2} \mathrm{O}$ salts were successively tested, using a platinum electrode to generate the spray. However, not only does the oxidation state not change the complexation efficiency dramatically, but none of the mass shifts obtained for those complexes $((\mathrm{Fe}-2 \mathrm{H})$ and $(\mathrm{Fe}-3 \mathrm{H})$ for the $\mathrm{Fe}(\mathrm{II})$ and the $\mathrm{Fe}(\mathrm{III})$ salts, respectively) corresponds to the mass shift obtained with the iron sacrificial electrode. Therefore, complex formation by using the sacrificial electrode does not follow the same pathway.
The formation of small clusters on the electrode could explain this unexpected behavior.

\section{On-line complexation with a silver electrode}

No complexation was observed with angiotensin after $10 \mathrm{~min}$ of infusion, even if silver has been found to form aqueous phase complexes with sulfur- and non-sulfur-bearing peptides and proteins. ${ }^{28}$ However, this result is in agreement with the classification of hard/soft metals and ligands. ${ }^{30}$ With the cysteine-containing peptide (AIKCTKPF), a single adduct is formed, as shown in Fig. 10. The mass shift corresponds to $(\mathrm{Ag}-\mathrm{H})$. The low complexation is due to the passivation of the electrode: an $\mathrm{AgCl}$ film is actually generated at the electrode surface during each experiment, therefore preventing the silver ions from reacting with the peptides.

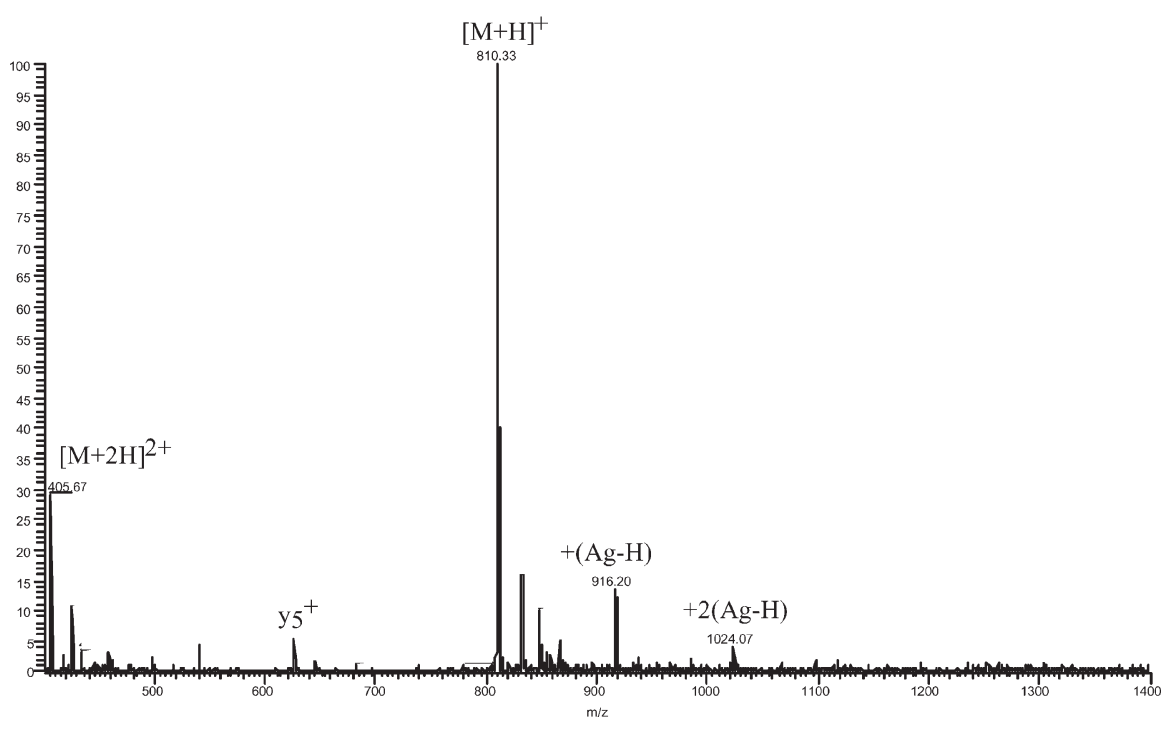

Figure 10. Full scan mass spectrum from the infusion of AIKCTKF using a silver electrode $(\mathrm{t}=3 \mathrm{~min}) . \quad[\mathrm{M}+\mathrm{H}]^{+}=810.33 ; \mathrm{m} / \mathrm{z} \quad(1: 1 \quad$ complex $)=916.20 ; \mathrm{m} / \mathrm{z} \quad(1: 2$ complex $)=1024.07$. 
Table 4. Adduct relative signal intensities after $5 \mathrm{~min}$ infusion $(100 \%=$ native peak) for each experiment

\begin{tabular}{lcccc}
\hline & AngII $+\mathrm{M}^{\mathrm{a}+}$ & Pep+M & AngII $+2 \mathrm{M}^{\mathrm{a}+}$ & Pep+2M \\
\hline $\mathrm{Cu}^{2+}$ & $58 \%$ & $55 \%$ & $5 \%$ & $61 \%$ \\
$\mathrm{Zn}^{2+}$ & $70 \%$ & $25 \%$ & $4 \%$ & $5 \%$ \\
$\mathrm{Fe}^{2+}$ & $9 \%$ & $7 \%$ & - & - \\
$\mathrm{Ni}^{2+}$ & $15 \%$ & $7 \%$ & - & - \\
$\mathrm{Ag}^{+}$ & - & $19 \%$ & - & $6 \%$ \\
\hline
\end{tabular}

\section{CONCLUSIONS}

The present paper demonstrates that on-line complexation based on the electrolytic behavior of a microspray chip is efficient and stable over time, allowing the study of the metalion/peptide complexes. Copper and zinc are particularly well suited for the generation of transition-metal cations and their on-line chelation to peptides, as shown by the complexation yields obtained (see Table 4). As mentioned earlier, their redox potentials and solvation times (see Tables 1 and 2) are the most suitable for an efficient on-line complexation.

Further investigations, such as measurement of $\mathrm{pH}$ conditions and solvent composition that are known to influence the spatial conformation of peptides, should be carried out. The detection of phosphorylated peptides could also be assessed since the immobilization through the phosphate groups occurs at low $\mathrm{pH}$, which favors signals of peptides in ESI-MS.

Considering that equivalent complexation was obtained with much higher salt concentration than is electrogenerated (see Experimental section), chelation probably occurs mainly in the microchannel, where small dimensions provide higher reaction yield. The electrode end is located at the inlet reservoir of the chip and, based on the computational studies of Van Berkel et al., ${ }^{39}$ metal ions are probably mainly generated at this extremity and migrate directly into the microchannel, towards the microspray outlet.

This easy-to-use microspray does not, however, guarantee steady-state mass transport, as illustrated by the change in signal-to-noise ratio in the case of the copper electrode. That is why a previously introduced microspray interface similar to the one used in this study could advantageously be substituted for the latter interface. That interface has been found to efficiently perform on-line electrochemically induced modification of peptides. ${ }^{40,41}$ It consists of a microchannel with a carbon band electrode at its bottom that can be plated with the metal of interest. In simple infusion configuration (pressure-driven pumping), laminar flows and steady-state regimes are obtained. These conditions are the most favorable for on-line complexation optimization, based mainly on the chip design. ${ }^{42}$ The use of an embedded sacrificial microelectrode should be a good option to enhance the on-line complex formation in a reproducible manner.

\section{Acknowledgements}

The authors would like to thank the Peptide and Protein Chemistry Laboratory at the BIL Biomedical Centre at Epalinges, Switzerland, for the synthesis of the cysteinyl peptide. Mr. Niels Lion and Dr. Christophe Roussel are also gratefully acknowledged for fruitful discussions.

\section{REFERENCES}

1. Nemirovskiy OV, Gross ML. J. Am. Soc. Mass Spectrom. 1996; 7: 977.

2. Porath J, Carlsson J, Olsson I, Belfrage G. Nature 1975; 258: 598.

3. Zhao H, Adams J. Int. J. Mass Spectrom. Ion Processes 1993; 125: 195.

4. Hu P, Gross ML. J. Am. Soc. Mass Spectrom. 1994; 5: 137.

5. Gatlin CL, Turecek F, Vaisar T. J. Mass Spectrom. 1995; 30: 1605.

6. Gatlin CL, Turecek F, Vaisar T. J. Mass Spectrom. 1995; 30: 1617.

7. Gatlin CL, Rao RD, Turecek F, Vaisar T. Anal. Chem. 1996; 68: 263.

8. Gatlin CL, Turecek F. J. Mass Spectrom. 1995; 30: 1636.

9. Alvarez EJ, Brodbelt JS. J. Am. Soc. Mass Spectrom. 1998; 9: 463.

10. Van Berkel GJ, Zhou FM. Anal. Chem. 1995; 67: 2916.

11. Blades AT, Ikonomou MG, Kebarle P. Anal. Chem. 1991; 63: 2109.

12. Van Berkel GJ. J. Mass Spectrom. 2000; 35: 773.

13. Van Berkel GJ, Asano KG, Schnier PD. J. Am. Soc. Mass Spectrom. 2001; 12: 853.

14. Van Berkel GJ, Kertesz V. J. Mass Spectrom. 2001; 36: 1125.

15. Mirza UA, Chait BT. Anal. Chem. 1994; 66: 2898.

16. Gobry V, van Oostrum J, Martinelli M, Rohner TC, Reymond F, Rossier JS, Girault HH. Proteomics 2002; 2: 405.

17. Sigel H, Martin RB. Chem. Rev. 1982; 82: 385.

18. Lacher NA, Garrison KE, Lunte SM. Electrophoresis 2002; 23: 1577.

19. Gawron AJ, Lunte SM. Electrophoresis 2000; 21: 2067.

20. Schwarz A, Bagel O, Girault HH. Electroanalysis 2000; 12: 811.

21. Gawron AJ, Lunte SM. Electrophoresis 2000; 21: 3205.

22. Gatlin CL, Turecek F, Vaisar T. J. Am. Chem. Soc. 1995; 117: 3637.

23. Kendrick MJ, May MT, Plishka MJ, Robinson KD. Metal Ions in Biological Systems. Ellis Horwood: Chichester, 1992.

24. Rossier JS, Youhnovski N, Lion N, Damoc E, Reymond F, Girault HH, Przybylski M. Angew. Chem. Int. Edn. Engl. 2003; 42: 53.

25. Bindila L, Froesch M, Lion N, Vukelic Z, Rossier JS, Girault $\mathrm{HH}$, Peter-Katalinic J, Zamfir A. Rapid Commun. Mass Spectrom. 2004; 18: 2913.

26. Hutchens TW, Allen MH. Rapid Commun. Mass Spectrom. 1992; 6: 469.

27. Hu P, Loo JA. J. Am. Chem. Soc. 1995; 117: 11314.

28. Li H, Siu KWM, Guevremont R, Le Blanc JCY. J. Am. Soc. Mass Spectrom. 1997; 8: 781.

29. Marzluff EM, Campbell S, Rodgers MT, Beauchamp JL. J. Am. Chem. Soc. 1994; 116: 7787.

30. Sigel A, Sigel H. Probing of Proteins by Metal Ions and Their Low-Molecular-Weight Complexes. Marcel Dekker: New York, 2001.

31. Katayama A, Kamidate T, Morita M, Watanabe H. Anal. Sci. 1991; 7: 633 .

32. Brust M, Blass PM, Bard AJ. Langmuir 1997; 13: 5602.

33. Zhang WW, Lu CS, Zou Y, Xie JL, Ren XM, Zhu HZ, Meng QJ. J. Colloid Interface Sci. 2002; 249: 301.

34. Jiao CQ Freiser BS. J. Am. Soc. Mass Spectrom. 1995; 6: 521.

35. Loo JA, Hu P, Smith RD. J. Am. Soc. Mass Spectrom. 1994; 5 : 959-965.

36. Smith AD, Moini M. Anal. Chem. 2001; 73: 240.

37. Nemirovskiy OV, Gross ML. J. Am. Soc. Mass Spectrom. 1998; 9: 1285.

38. Landolt D. In Traite des Materiaux, vol. 12, PPUR: Lausanne, 1993; 316-324.

39. Van Berkel GJ, Giles GE, Bullock JS, Gray LJ. Anal. Chem. 1999; 71: 5288.

40. Rohner TC, Rossier IS, Girault HH. Anal. Chem. 2001; 73: 5353.

41. Rohner TC, Rossier JS, Girault HH. Electrochem. Commun. 2002; 4: 695.

42. Van Berkel GJ, Asano KG, Kertesz V. Anal. Chem. 2002; 74: 5047. 